\title{
Pamela Hardy: the pre-hospital specialist
}

\author{
Anne Gulland
}

\section{BMJ Careers}

Having grown up in Nottingham, Pamela Hardy is now an emergency care consultant in the north of Scotland. Her "life's too short" attitude has led to a hugely varied career and meant she has done things she never thought possible.

\section{Early life}

I went to a comprehensive school on a council estate in Nottingham where it wasn't really "the thing" to go to university. I was planning to do midwifery training when someone suggested I do medicine. I was relatively bright at school but worked hard because I was bullied. I didn't get in first time round and had to re-sit my A levels. When I got my results, I ran down the road after my dad, who was on his way to work as a mechanic, to tell him that I was going to medical school. I've always had incredible support from my parents and family.

\section{Feeling useless}

After initial training in paediatrics I moved back to Nottingham and started doing a mixture of adult and paediatric emergency. It was during this time that pre-hospital care was developing. Like so many people who got involved in the specialty in the early days, I came across a car crash and stopped to help but felt useless. Afterwards I got some kit together and put it in a bag in the car.

\section{Air ambulance}

When I was an emergency medicine registrar in Nottingham, patients started coming in by air ambulance. I had done some pre-hospital care courses and was about to sit the diploma in immediate care. The helicopter crew invited me to join them and I ended up doing informal shifts. In 2008 I started working for Derbyshire, Leicestershire, and Rutland Air Ambulance and I still come down from Scotland to do shifts every month. It has evolved into a very structured, well governed service. We do anaesthesia at the roadside and surgical interventions, including opening the chest and amputations.

\section{Life is too short}

I became an emergency medicine consultant but various life events, including a former partner being diagnosed with terminal cancer shortly after we separated, led to my "life's too short" moment. I took a year's unpaid leave as there was no other way I could be a carer for him, but he died six days into my leave. For some time I had been threatening to escape to the far north of Scotland, although I knew nothing about it and no one there. I saw an advert for Dr Gray's Hospital in Elgin and went for it.

\section{Fat, wheezy child}

When I moved here I intended to be a hermit and do what I wanted and nothing else. But I found a trail and a beach and finally realised a dream of being able to run $5 \mathrm{~km}$ and now have an array of medals for $10 \mathrm{~km}$ runs. I was a fat, wheezy child and my PE teachers would never believe it! I love it here-the space, the scenery, and the people.

\section{A privilege}

When the search and rescue service was still with the Royal Air Force (until 2015) I had the incredible experience of going out in their Sea King helicopter and seeing some amazing flying and rescue situations. I have winched in various settings, such as on Ben Nevis and onto a tiny boat in the North Sea. One sunny afternoon I was being winched off the mountain looking at the Great Glen. I couldn't believe that a woman of my age was doing it. I have a picture of myself and the winchman with our feet sticking out of the cabin looking up the Great Glen. It was such a privilege to be able to experience that.

\section{Target culture}

I couldn't work in the NHS in England again as the target culture is so tough. We do have targets here and we have to manage the flow of patients, but there is a more positive attitude. The Scottish health minister visited recently and there is better engagement and a "realistic medicine" focus. The system seems a little bit kinder here.

\section{Department in disarray}

When I came into this job, the Scottish government and Royal College of Emergency Medicine had carried out a review into whether Elgin, the smallest district general hospital in the country, needed an emergency department. It was described as an emergency department in disarray. At that time, it was operating as an old fashioned casualty unit, led by GPs with specialty support. I set up a consultant led emergency department from scratch. We see 25000 patients a year, which is tiny compared with most other emergency departments, but we have the same pressures and congestion as other places. 


\section{Faculty of Pre-Hospital Care}

The progress in the field of pre-hospital care over my career has been phenomenal -it's gone from a side interest to a fully fledged sub specialty. I was one of the founder members of the faculty and we approached the Royal College of Surgeons of Edinburgh as we were looking for a home and wanted to develop exams and set standards. We have always agreed that it's a multi-disciplinary specialty-and now paramedics and nurses can all access the diploma and fellowship exams and have the same post-nominals as the doctors.

\section{Curriculum vitae:}

2017 to date: Co-vice chair, Faculty of Pre-Hospital Care

2011 to date: Lead consultant in emergency medicine, Dr Gray's Hospital, Elgin

2008 to date: Clinical supervisor, Derbyshire, Leicestershire, and Rutland Air Ambulance

2003 to 2011: Consultant in emergency care, Chesterfield Royal Hospital 2003 to 2005: Clinical director, East Midlands Ambulance Service 2001 to 2003: Consultant in accident and emergency, King's Mill Hospital, Mansfield

1996 to 2001: Emergency medicine training, Nottingham, Derby, Mansfield, Sheffield

1983 to 1988: Sheffield University medical school 